\title{
ULTRASONIC MEASUREMENTS OF BURNING RATES IN FULL-SIZE ROCKET MOTORS
}

\author{
H. Kurabayashi ${ }^{1}$, A. Sato ${ }^{1}$, K. Yamashita ${ }^{1}$, H. Nakayama ${ }^{1}$, \\ K. Hori' ${ }^{2}$, M. Honda ${ }^{2}$, and K. Hasegawa ${ }^{2}$ \\ ${ }^{1}$ IHI Aerospace Co., Ltd. \\ Japan \\ ${ }^{2}$ Japan Aerospace Exploration Agency \\ Japan
}

A new ultrasonic sounding technique to measure the instantaneous propellant thickness in a solid rocket motor has been developed and was used successfully in the static firing tests with full-size motors. The technique applies a low-frequency ultrasonic wave (50 or $100 \mathrm{kHz})[1,2]$. Sets of transducers were installed in the motor case using magnets, with each set comprising a transmitter/receiver and receivers. Transducer installation required careful setup to maintain good acoustic coupling between each transducer and motor case and to withstand the harsh vibrations of the environment. Time histories were obtained for the propellant thickness at various locations during the burning tests. This paper presents in detail the ultrasonic sounding and installation techniques and the results obtained.

\section{INTRODUCTION}

In the Japan space development program, solid propellants have been widely used in the world's largest M-V solid rocket for launching satellites for scientific or engineering experiments. As shown in Fig. 1, a solid rocket motor has a laminated structure consisting of metal housing, rubber insulation, and solid propellant grain. The web thickness of the solid propellant decreases during combustion, as shown in Fig. 1.

A solid rocket motor propellant composed of polybutadiene and oxidant generates powerful propulsion. One can estimate the propulsive performance of a rocket motor by measuring the burning rate of the sample propellant before loading into the motor. (The estimated value is ultimately verified in a full-scale static firing test.) Through these performance evaluations of rocket motors, the development of the propellant surface shown in Fig. 1 was addressed. Reduction of the propellant thickness during combustion was studied using the

This is an Open Access article distributed under the terms of the Creative Commons Attribution-Noncommercial License 3.0, which permits unrestricted use, distribution, and reproduction in any noncommercial medium, provided the original work is properly cited. 

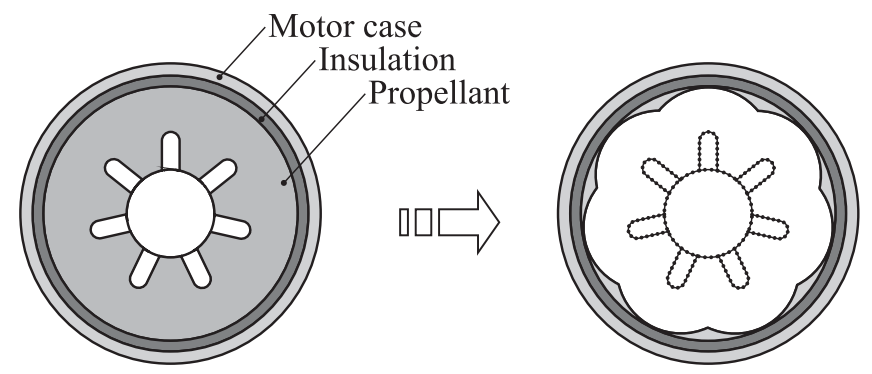

Figure 1 Reduction of propellant thickness during combustion

measurement method based on ultrasonic waves to permit nondestructive measurements [3]. Applying this method to a full-scale solid rocket motor may improve the precision of a rocket motor design. Additionally, this method may permit the observation of erosive burning based on measurements along the axial direction of the motor.

This paper introduces this method with a focus on the results of measurements.

\section{ULTRASONIC MEASUREMENT SYSTEM}

\subsection{Principles of Ultrasonic Measurement}

During the measurements of propellant thickness the ultrasonic pulse propagates to the propellant from the side of the motor case. Figure 2 shows the conditions of ultrasonic pulse propagation. The difference in the acoustic impedances of the motor case made of high-tensile (HT) steel and insulation is significant, and virtually all ultrasonic pulses generate multiple reflections, as shown in Fig. $2 a$.

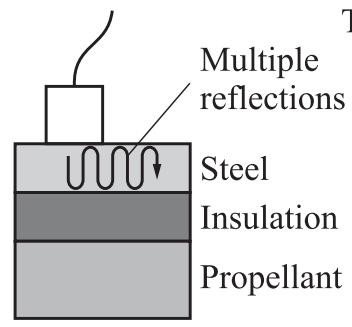

(a)

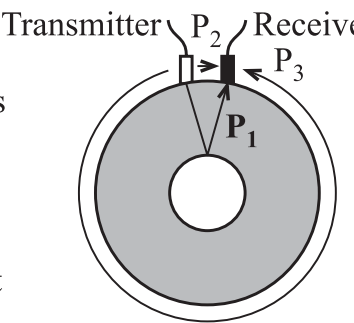

(b)

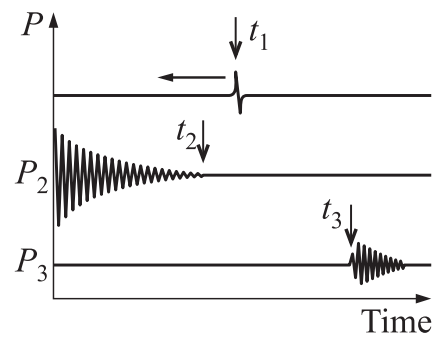

(c)

Figure 2 Principle of measurements 
In Fig. $2 b, \mathrm{P}_{1}$ corresponds to an echo from the inner surface of the propellant, $\mathrm{P}_{2}$ to multiple echoes from the motor case or insulation, and $\mathrm{P}_{3}$ to echoes at the circumference of the motor case. The ultrasonic velocity in the propellant is approximately one-third of that in the motor case. Based on the differences in the propagation times of each echo, as shown in Fig. $2 c$, the reflected echo $\mathrm{P}_{1}$ can be distinguished from multiple echoes $\mathrm{P}_{2}$ of the motor case and from $\mathrm{P}_{3}$. Since the propellant thickness gradually decreases during combustion, the propagation length $\mathrm{P}_{1}$ decreases likewise. As the echo $\mathrm{P}_{1}$ in Fig. $2 c$ moves to the left, it gradually becomes buried in the multiple echoes of $\mathrm{P}_{2}$.

\subsection{Identifying a Suitable Frequency}

The propellant and insulation of solid rocket motors are known to be highly acoustic-damping materials. In the frequency band of a few megahertz of metals,

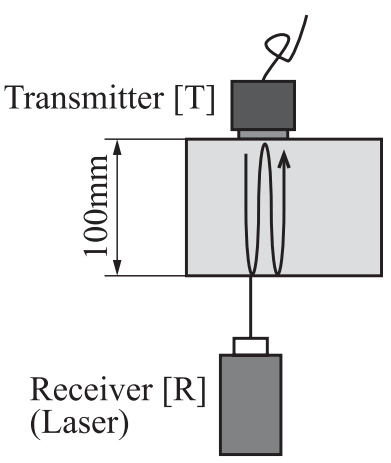

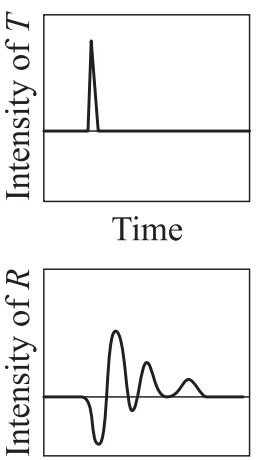

Time

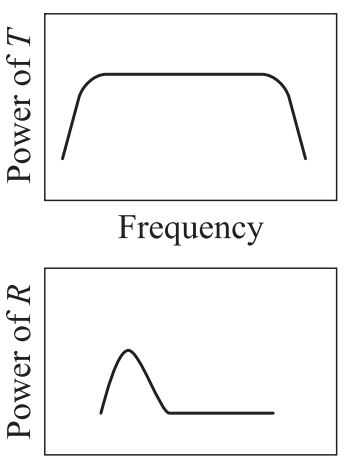

Frequency

(a)

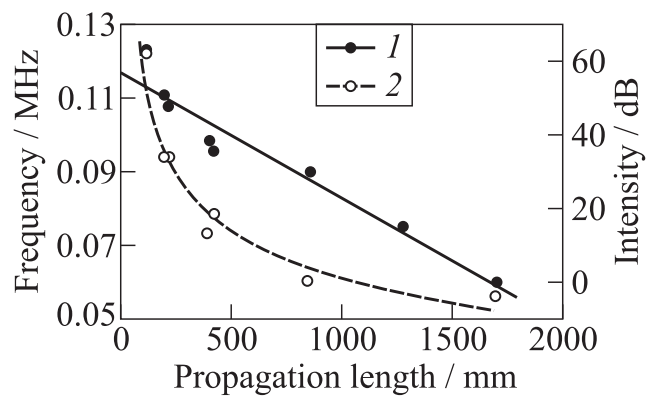

(b)

Figure 3 Investigation of ultrasonic characteristics of propellant: (a) setup configuration; and $(b)$ result $(1$ - intensity and 2 - center frequency) 
the acoustic damping by the materials and transmission distance is too high to detect the ultrasonic echoes. Therefore, a new frequency had to be identified that would make it possible to detect ultrasonic echoes in a thick propellant. Figure $3 a$ shows the experimental configuration used to identify an appropriate frequency. The thickness of the propellant was $100 \mathrm{~mm}$. A wave was repeatedly reflected at the upper and lower surfaces and gradually attenuated. A laser beam measurement system was used to detect the vibration frequency of each reflecting wave at the lower surface. Figure $3 b$ shows the center frequency and amplitude of the reflected wave relative to the propagation length. For example, if the propagation length of propellant was approximately $200 \mathrm{~mm}$, a frequency of approximately $100 \mathrm{kHz}$ would be well suited.

\subsection{Measurement System Configuration}

Figure $4 a$ is a schematic diagram of the ultrasonic measurement system developed for this study. One set of transducers consists of a transmitter/receiver and two receivers. The transducers are placed along the longitudinal or hoop axis of the motor case. The return echo from the burning surface of the propellant is acquired by these transducers. During firing tests, this system transmits ultrasonic waves at $10 \mathrm{~Hz}$.

The vibration environment on the firing motor case tends to be quite harsh. The transducer installation requires careful setup to maintain good acoustic coupling between the transducer and the motor case. As shown in Fig. 4, each transducer is placed into a metal holder. The end of the holder is curved to fit the radius of the motor housing, and the periphery of the holder is bonded to the motor case using an epoxy adhesive. The gap between the transducer and the motor surface is filled with grease to maintain adequate acoustic coupling.

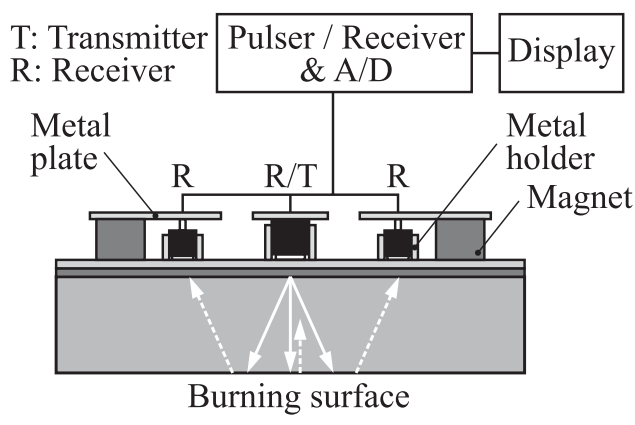

(a)

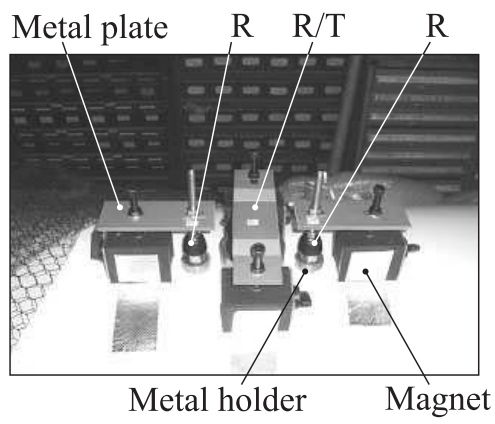

(b)

Figure 4 Measurement system: (a) block diagram of measurement system; and (b) setup of transducers 
Additionally, the transducer is pressed toward the motor case surface by a metal plate held in place by a strong magnet attachment. Figure $4 b$ illustrates this setup.

\section{APPLICATION TO STATIC FIRING TESTS OF FULL-SIZE MOTORS}

\subsection{Target Motors}

The target motors to which ultrasonic measurements were applied were the NAL735 and M-24 rocket motors. Table 1 gives the characteristics of these rocket motors.

The NAL-735 solid rocket motor was originally developed for an experimental JAXA supersonic aircraft. In the forward part of NAL-735, the cross section is circular. The cross section of the afterpart assumes the shape of a seven-pointed star. Since the length/diameter ratio of the NAL-735 motor is quite large, the rocket motor tends to generate erosive burning. An M-24 solid rocket motor was also developed as a second stage motor for the M-V rocket. The cross section of M-24 is a seven-pointed star. Figure 5 shows the configurations of these motors. In these figures, $A, B, C$, and $D$ correspond to the locations of the transducers.

Table 1 Features of rocket motors

\begin{tabular}{lcc}
\hline Rocket motor & NAL-735 & M-24 \\
\hline Diameter & $732 \mathrm{~mm}$ & $2,560 \mathrm{~mm}$ \\
Length & $8,680 \mathrm{~mm}$ & $5,610 \mathrm{~mm}$ \\
\hline Maximal web thickness & $243 \mathrm{~mm}$ & $1,019 \mathrm{~mm}$ \\
Propellant mass & $3,515 \mathrm{~kg}$ & $31,224 \mathrm{~kg}$ \\
Burning rate $\left(\right.$ at $\left.20{ }^{\circ} \mathrm{C}, 5 \mathrm{MPa}\right)$ & $5.79 \mathrm{~mm} / \mathrm{s}$ & $8.79 \mathrm{~mm} / \mathrm{s}$ \\
Effective burn time $($ predictive value) & $46.5 \mathrm{~s}$ & $76.3 \mathrm{~s}$ \\
Maximal pressure $\left(\right.$ at $\left.10^{\circ} \mathrm{C}\right)$ & $4.0 \mathrm{MPa}$ & $5.2 \mathrm{MPa}$ \\
Motor case material & $\mathrm{HT} \mathrm{steel}$ & $\mathrm{HT}$ steel \\
Propellant materials & AP/HTPB $/ \mathrm{AL}$ & $\mathrm{AP} / \mathrm{HTPB} / \mathrm{AL}$ \\
\hline
\end{tabular}

Remarks: AP — Ammonium Perchlorate; HTPB — Hydroxyl Terminated PolyButadiene; $\mathrm{Al}$ - Aluminum.

\subsection{Static Firing Tests and Results}

A static firing test of the NAL-735 was carried out in December 2007 and of M-24 in March 2008. These tests were completed successfully, generating several types of basic data, including ultrasonic data. 


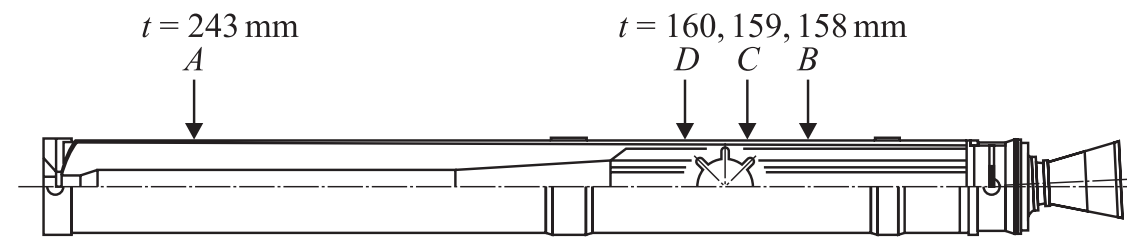

FWD

AFT

(a)

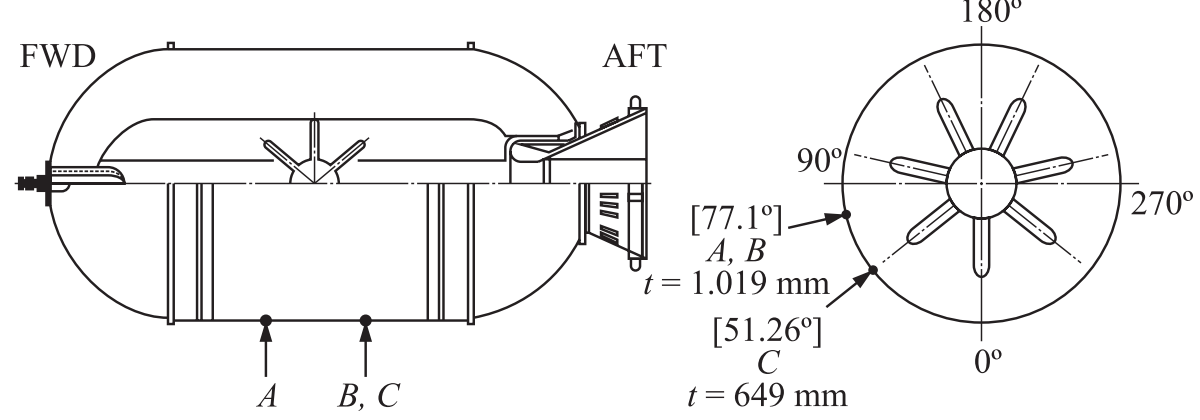

(b)

Figure 5 Configurations of NAL-735 (a) and M-24 (b) rocket motors $(t$ - web thickness)

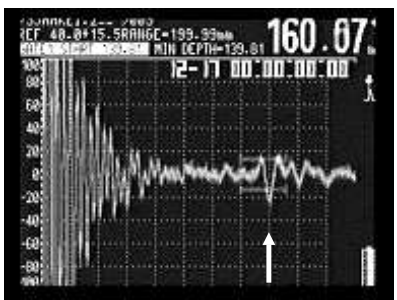

(a)

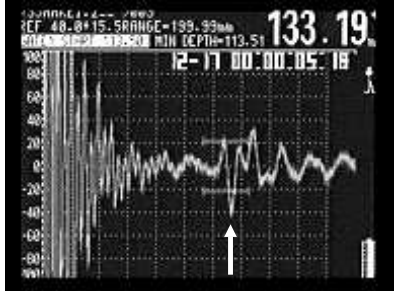

(b)

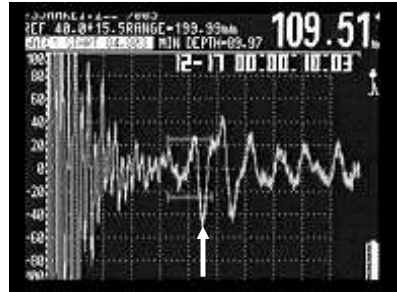

(c)

Figure 6 Shift in echo from the burning surface at position $D$ of NAL-735 motor: (a) $0 \mathrm{~s}$; (b) 5 ; and (c) $10 \mathrm{~s}$

Figure 6 shows echo data for location $D$ of the NAL-735 [4]. The horizontal axis shows the time of flight, while the longitudinal axis shows the amplitude. The echo indicated by the arrow is the wave reflected from the burning surface of the propellant. The waveform of the propellant surface goes from right to left, corresponding to the decreasing web thickness. In the burnout phase of 

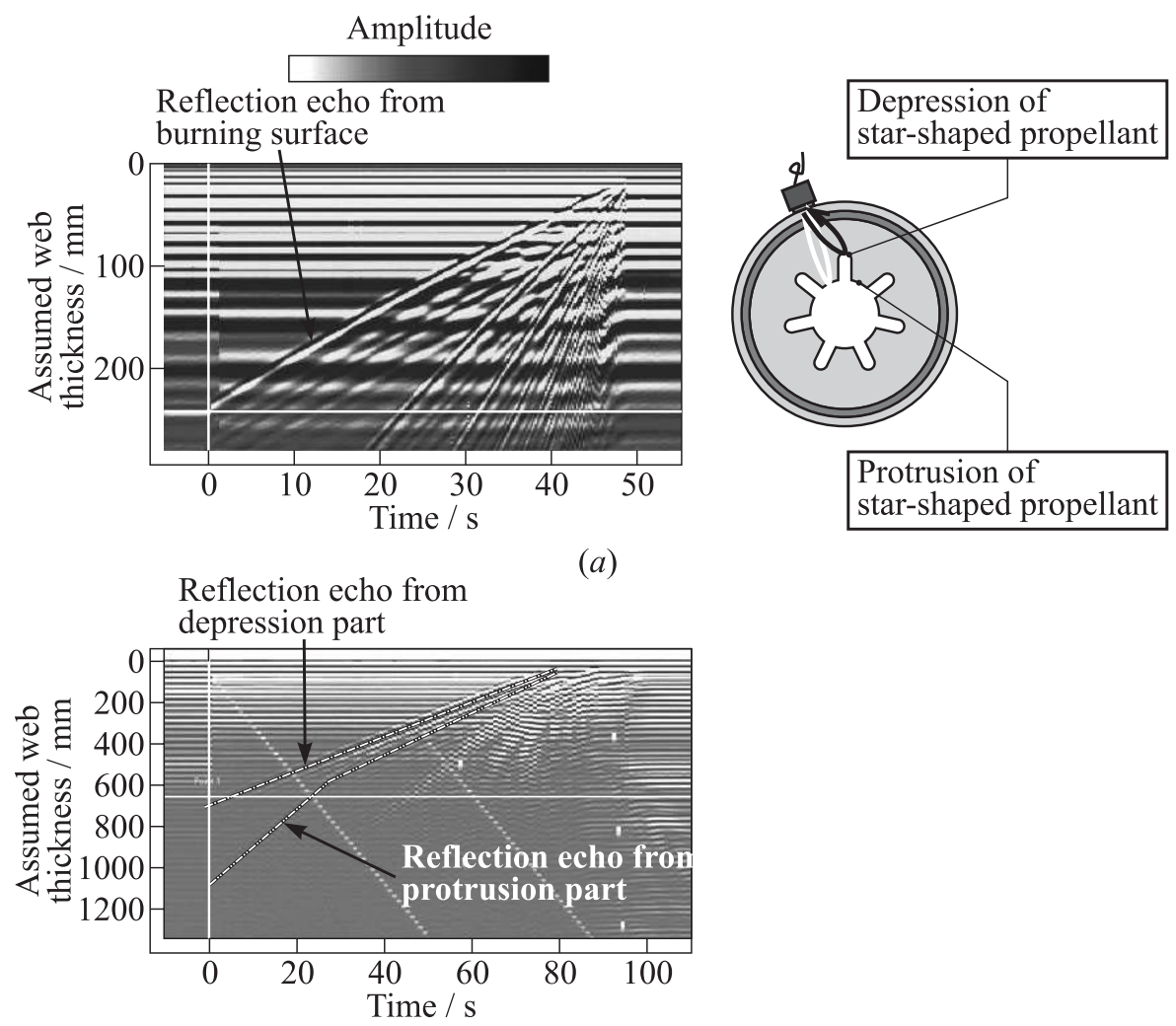

(b)

Figure 7 Time history of assumed web thickness at $\mathrm{A}_{1}$ of NAL-735 (a) and M-24 (b) motors

combustion, the echo is buried in multiple echoes in the left side of each image and becomes undetectable on this monitor. The multiple echoes are treated as multiple reflections from the motor case and the insulation.

As mentioned above, it is highly difficult to detect and trace moving echoes automatically. To identify the echo continuously, a simple image enhancement method was used. At first, each waveform (for example, the one depicted in Fig. 6) is converted into a straight line colored by gradation from dark blue to white, based on its amplitude. The positive amplitude is colored by white, while the nagative amplitude is colored by dark. By converting all echo charts and arranging them in a timeline, one obtains a map. Figure 7 shows the examples of the map for A1 output from NAL-735 (Fig. 7a) and that of M-24 (Fig. 7b). The horizontal axis is the time elapsed from ignition, while the vertical axis indicates the web thickness calculated assuming a constant wave velocity. One can 
easily identify numerous straight white lines in the map. Each inclined line is the reflected echo of some part of the propellant grain in the rocket motor. This method makes it possible to trace the movement of an echo quite easily, even if the reflected echo is buried in other echoes, like the multiple reflections from the motor case and insulation at a given instant of time. In Fig. $7 b$, one can detect the reflected echoes of the depressions and protrusions of the star-shaped cross section because the angle of the beam spread is wide and the length of propagation through the propellant is long.

\section{VERIFICATION OF MEASUREMENT RESULTS}

\subsection{Calibration of Wave Velocity}

Temperature and pressure affect wave velocity. The data from the firing test need to be corrected based on the initial propellant temperatures and the instantaneous operating pressure of the firing motor.

There are two methods for correcting the wave velocity depending on temperature. The first (Method 1) uses the data for a propellant specimen. In contrast, the second (Method 2) uses echoes from the inner surface of the propellant of a full-size motor before the static firing test.

Method 1 uses the data like those shown in Fig. 8 [4]. This figure shows wave velocities with respect to the temperature and pressure of the NAL-735 propellant. The data for Fig. 8 were measured using a specimen $50 \mathrm{~mm}$ long and cut from the propellant block. The specimen was clipped by an ultrasonic

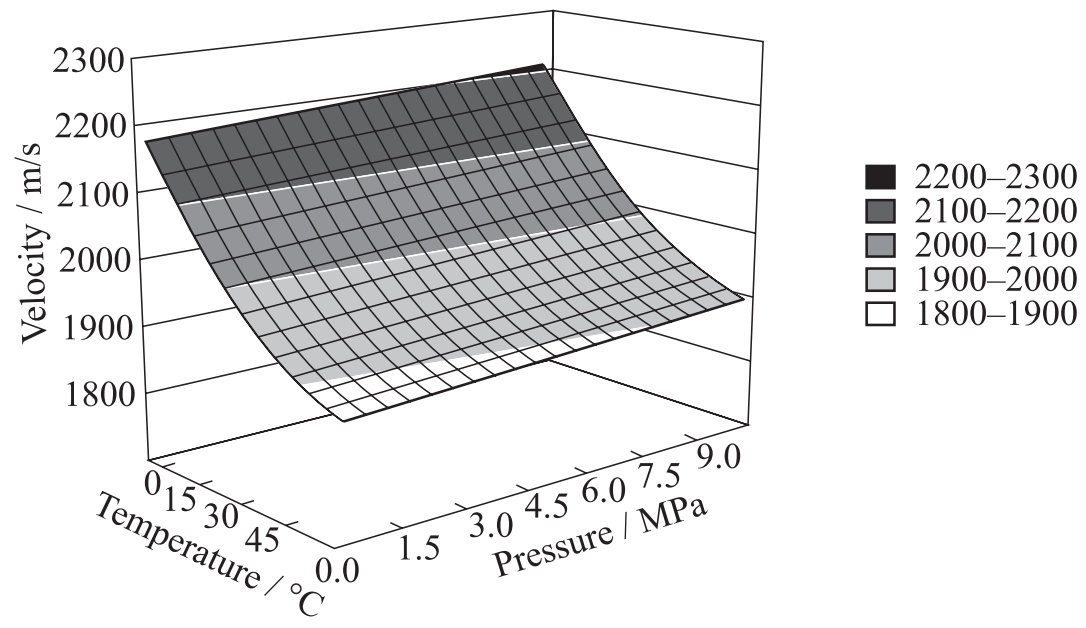

Figure 8 Dependencies of the ultrasonic wave velocity on temperature and pressure 


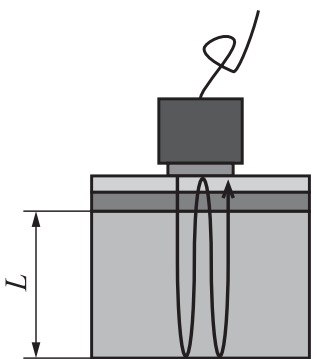

B1 B2

B1: Primary reflected echo

B2: Secondary reflected echo

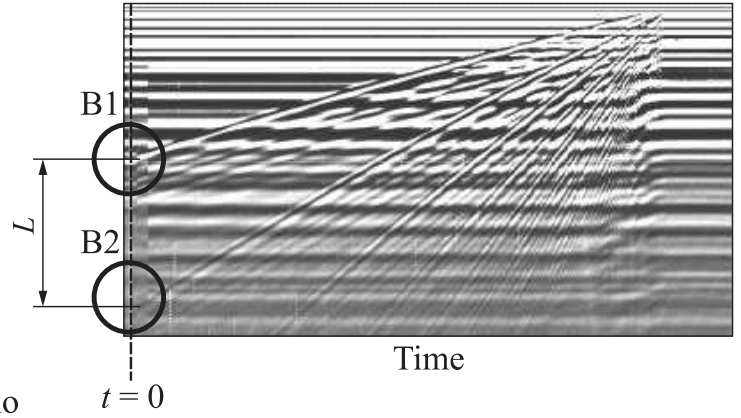

Figure 9 Calculation of wave velocity by primary and secondary reflected echos

transmitter and a receiver and encapsulated into a metal container with a heater. The container was pressurized by nitrogen gas. The wave velocities were measured by changing the temperature (from 0 to $60^{\circ} \mathrm{C}$ ) and pressure (from 0.1 to $10 \mathrm{MPa}$ ). The wave velocity is seen to increase with pressure as a linear function and decrease with the temperature as a quadratic function.

Figure 9 shows the principles underlying Method 2. One can calculate the velocities based on the initial web thickness and propagation times. If one calculates the velocity by the propagation time of the primary reflected echo, the calculations cannot be precise since the timing of the ultrasonic transmission cannot be precisely detected due to multiple echoes from the left side of the waveform (see Fig. 6). However, one can calculate the velocities precisely using the difference of the propagation time between the primary reflected echo and the secondary echo.

For Method 1, the wave velocity at $12.5^{\circ} \mathrm{C}$ and ambient pressure of the NAL735 propellant in the static firing test was $2079 \mathrm{~m} / \mathrm{s}$ (see Fig.8). In contrast, if one applied Method 2, the velocity was $2069 \mathrm{~m} / \mathrm{s}$ at ambient pressure. Thus, the correction velocity is approximately equal for both methods. So, the wave velocity was corrected using Method 2. Additionally, Fig. 8 was used to correct its value for the effect of pressure. As for M-24 motor, the same correction procedure as for NAL-735 was applied. For the M-24 motor, Method 2 was also applied. The wave velocity at $5{ }^{\circ} \mathrm{C}$ and ambient pressure was $2018 \mathrm{~m} / \mathrm{s}$.

\subsection{Evaluation of Burning Rate Data}

Ordinarily, the burning rate $r_{b}(\mathrm{~mm} / \mathrm{s})$ of solid propellants is calculated as follows:

$$
r_{b}=a P c^{n}
$$




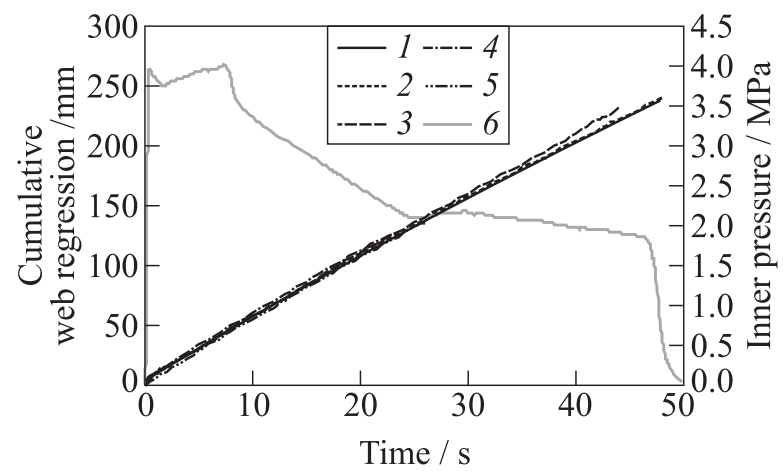

(a)

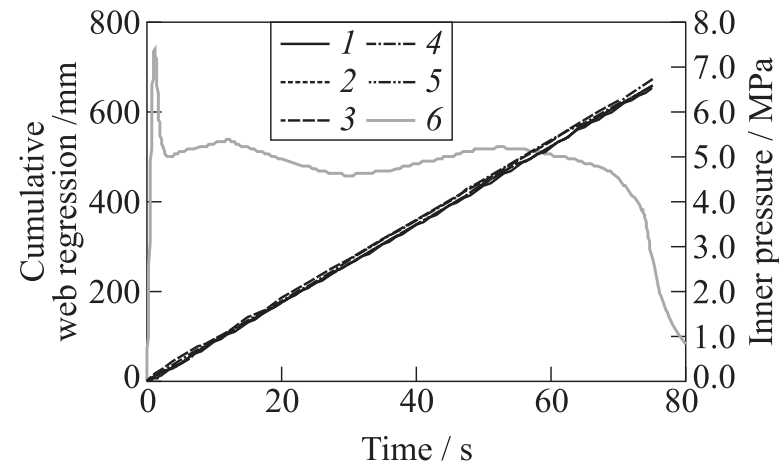

(b)

Figure 10 Cumulative web regression at the depression part of NAL-735 (a) and M-24 (b) motors: 1 - calculations using Eq. (1); 2 - measurements at A1; 3 - at $\mathrm{A} 2 ; 4$ - at B1; 5 - measurements at $\mathrm{C} 1$; and 6 - pressure

where $P_{c}$ is the burning pressure, $\mathrm{MPa}$; and $a$ and $n$ are the constants obtained from a firing test of sample motors using the same propellant as in the full-size rocket motors.

To verify the ultrasonic measurement data, the burning rates measured with ultrasonic waves were compared with the burning rates given by Eq. (1). Equation (1) was applied to the measured combustion pressure in the firing test. Figure $10 a$ shows a comparison of the cumulative web regression at A1, A2, B1, and $\mathrm{C} 1$ given by Eq. (1) for NAL-735, while Fig. $10 b$ shows the same for M-24 at the depression of the star-shaped cross section. Figure 11 shows the changes in the burning rates per measurement interval (1 s) based on the data in Fig. 10.

The results of ultrasonic measurements presented in Fig. 10 correspond to cumulative web regression from $t=0$, when combustion started. The cumula- 


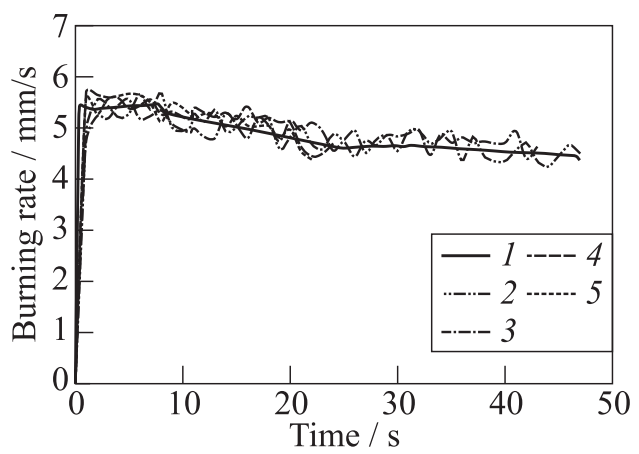

(a)

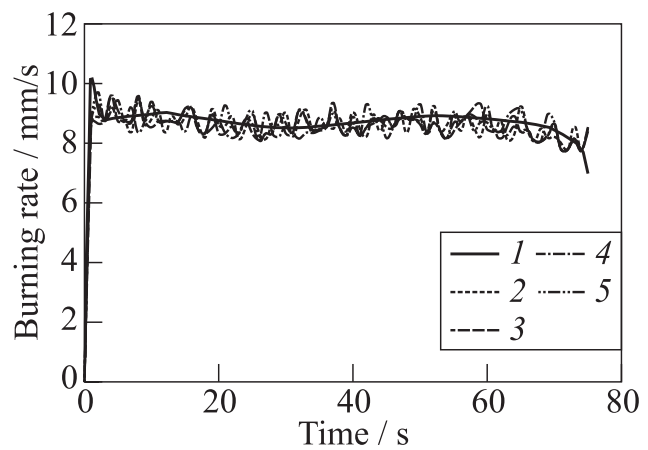

(b)

Figure 11 Time history of the burning rate for NAL-735 (a) and M-24 (b) motors: 1 - calculations using Eq. (1); 2 - measurements at A1; 3 - at A2; 4 - at B1; and 5 - measurements at $\mathrm{C} 1$

tive web regression was obtained after manually digitizing the white line that represents the second-by-second maximum value of the reflection echo based on the map like that shown in Fig. $7 b$ and 8. The corrections were applied to each one-second datum of ultrasonic measurements based on temperature and combustion pressure assuming that temperatures inside the propellant do not change during combustion.

In Fig. $10 a$, the average burning rate indicated by ultrasonic measurements at $A, B$, and $C$ is approximately $5.3 \mathrm{~mm} / \mathrm{s}$ during the period from 0 to $25 \mathrm{~s}$. In contrast, the average burning rate given by Eq. (1) is $5.2 \mathrm{~mm} / \mathrm{s}$. The two results are in good agreement. After $25 \mathrm{~s}$, the inner pressure is less than that before $25 \mathrm{~s}$, the average burning rate of $A$ is $5.0 \mathrm{~mm} / \mathrm{s}$, and the average burning rate given by Eq. (1) is $4.9 \mathrm{~mm} / \mathrm{s}$. Additionally, the regression of the web at points $A, B$, and $C$ located along the axial direction of the motor is approxi- 
mately the same. Based on this evidence, one concludes that no erosive burning occurs.

In Fig. 10b, the cumulative web regression indicated by the ultrasonic measurements at points $A, B$, and $C$ are in good agreement. The average burning rates are $8.8 \mathrm{~mm}$, while the average burning rate given by Eq. (1) is $8.7 \mathrm{~mm} / \mathrm{s}$. Again, these results are in good agreement, as with the results for NAL-735. The inner pressure does not fluctuate significantly, and the burning rate is nearly constant during combustion. Based on this evidence, one can conclude that no erosive burning occurs.

As shown by the graphs in Fig. 11, second-by-second changes in the burning rates obtained by ultrasonic measurements for both rocket motors agree with the results given by Eq. (1). However, the data fluctuations are significant. They are ascribed to errors in reading the ultrasonic data; as previously described, these data were read manually from the images like those shown in Fig. 7. This process needs to be improved to achieve a higher precision.

\subsection{Issues for the Future}

As shown in Fig. 7b, ultrasonic echoes from the protrusion of the star-shaped cross section of the M-24 motor can be detected. Measuring the echoes from each part of the star-shape should help visualize the transformation of the burning surface during combustion. As the first step, the following case was examined.

Figure 12 is the result of a simple numerical simulation that shows the transformation of a star-shaped block of propellant of the M-24 rocket motor during combustion. Figure 13 is a comparison of the regression of the web at the protrusion of the star-shaped propellant cross section in the simulation like that shown in Fig. 12 and in the ultrasonic measurement. According to Fig. 13, the simulation gives longer times than the results actually measured for the propagation of reflected echoes during the first half of combustion. This may indicate differences in echo reflecting surfaces. Although the simulation is based on a

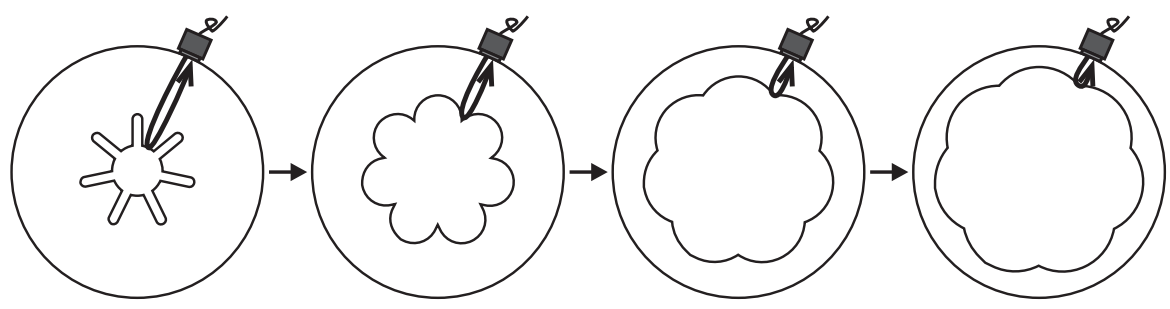

Figure 12 Simulated transformation of the star-shaped propellant of M-24 motor during combustion 
simplified model that does not precisely simulate actual combustion patterns, the measured reflected echo is believed to correspond to the pattern shown in Fig. 14.

As a matter of fact, it is possible that an echo from the side of one of the arms making up the star-shaped cross section was actually measured. Consequently, one can confirm the propagation path of ultrasonic waves in a specimen of a star-shaped material like that shown in Fig. 15, to simulate the transformation of the propellant surface during combustion.

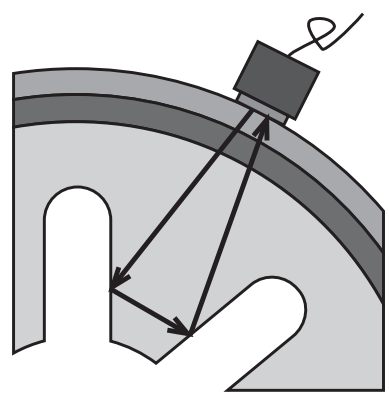

Figure 14 Assumed path of ultrasonic wave propagation

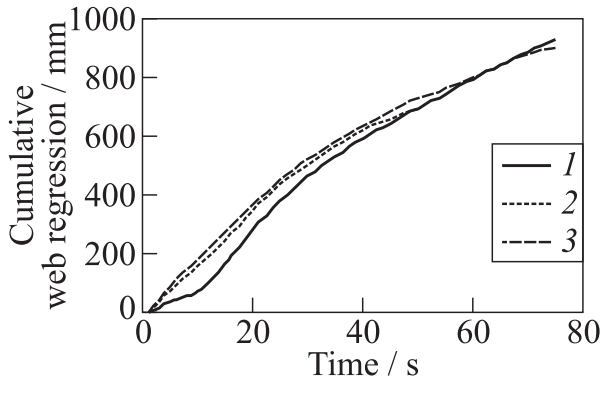

Figure 13 Comparison of propellant web regression at the star-shaped protrusion of M-24 motor: 1 - simulation; 2 and 3 - measurements at $\mathrm{A} 1$ and $\mathrm{A} 2$, respectively

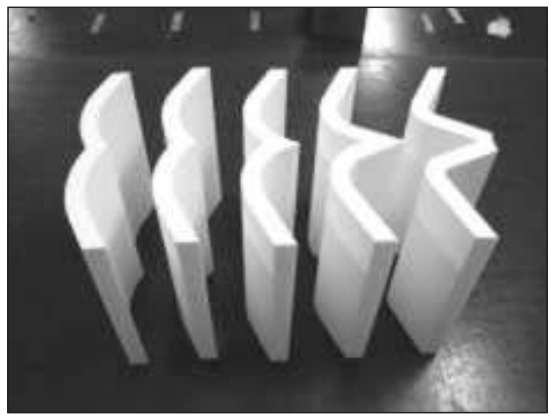

Figure 15 Simulated star-shaped specimen

\section{CONCLUDING REMARKS}

In the static firing tests, the regression of propellant web thickness was measured with low-frequency ultrasonic waves in the burning full-size rocket motors. Based on the results obtained, the average burning rate derived from the ultrasonic measurements appeared to agree well with the values calculated based on the inner pressure. The average burning rate for the entire rocket motor is usually known. In contrast, improving the precision of ultrasonic measurements will make it possible to assess the burning rate in each part of the rocket motor. 
Thus, it is believed that measuring the burning rates with ultrasonic waves will improve precision in combustion analyses of solid propellant grain.

\section{REFERENCES}

1. Cauty, F., C. Carmicino, and R. Sorge. 2005. The pressure sensitivity of the ultrasonic waves velocity: A contribution to a better determination of the energetic material regression rate. 6th ISICP Proceedings. Eds. K. K. Kuo and J. D. Rivera. 741-66.

2. Cauty, F., G. Louaze, and C. Erades. 2007. Ultrasound method: towards the automation of the solid propellant burning rateburn rate determination. 7th ISICP Proceedings. Eds. K. K. Kuo and K. Hori. 660-79.

3. Hasegawa, K., Y. Yamaya, and K. Hori. 2004. A new technology for the measurement of linear burning rateburn rates of solid propellants by means of ultrasonics. Sci. Technol. Energetic Materials 65(3):82-87.

4. Honda, M., T. Ohnuki, K. Hori, K. Hasegawa, A. Sato, and H. Kurabayashi. 2008. A new ultrasonic technique in static firing test of full size solid rocket motor. International Workshop HEMs-2008. Book of Abstracts. 75. 